\title{
Deformation Behavior and Tensile Properties of the Semi-Equiaxed Microstructure in Near Alpha Titanium Alloy
}

\author{
Minglang Luo ${ }^{1,2,3}$, Tingyi Lin ${ }^{1,2,3}$, Lei Zhou ${ }^{1,2,3}$, Wei Li 1,2,3 $\mathbb{D}$, Yilong Liang 1,2,3, Moliu Han 1,2,3 \\ and Yu Liang $1,2,3, *$
}

check for

updates

Citation: Luo, M.; Lin, T.; Zhou, L.; Li, W.; Liang, Y.; Han, M.; Liang, Y. Deformation Behavior and Tensile Properties of the Semi-Equiaxed Microstructure in Near Alpha Titanium Alloy. Materials 2021, 14, 3380. https://doi.org/10.3390/ ma14123380

Academic Editor: Andrey Belyakov

Received: 24 May 2021

Accepted: 17 June 2021

Published: 18 June 2021

Publisher's Note: MDPI stays neutral with regard to jurisdictional claims in published maps and institutional affiliations.

Copyright: (c) 2021 by the authors. Licensee MDPI, Basel, Switzerland. This article is an open access article distributed under the terms and conditions of the Creative Commons Attribution (CC BY) license (https:// creativecommons.org/licenses/by/ $4.0 /)$.
1 College of Materials and Metallurgy, Guizhou University, Guiyang 550025, China; minglangluo@163.com (M.L.); lintingyi2010@163.com (T.L.); zhoulei294117973@163.com (L.Z.); wli1@gzu.edu.cn (W.L.); ylliang@gzu.edu.cn (Y.L.); monewcold@163.com (M.H.)

2 Guizhou Key Laboratory for Mechanical Behavior and Microstructure of Materials, Guizhou University, Guiyang 550025, China

3 National \& Local Joint Engineering Laboratory for High-Performance Metal Structure Material and Advanced Manufacturing Technology, Guiyang 550025, China

* Correspondence: yliang2@gzu.edu.cn

\begin{abstract}
The tensile deformation and fracture behavior of a particular semi-equiaxed microstructure (S-EM) in a near alpha titanium alloy TA19 are investigated by an in situ method. In the S-EM, the thin $\beta$ lamellae grow through the equiaxed $\alpha_{p}$ phase $\left(\alpha_{p}\right)$, and the original $\alpha_{p} / \beta_{\text {trans }}$ interface in the bimodal microstructure largely disappears, forming a blurry interface between the semi-equiaxed $\alpha_{p}$ phase (equiaxed $\alpha_{p}$ phase that is grew through by the thin $\beta$ lamellae) and the transformed $\beta$ microstructure $\left(\beta_{\text {trans }}\right)$. The formation of dense slip bands inside the semi-equiaxed $\alpha_{p}$ phase in the $\mathrm{S}-\mathrm{EM}$ is inhibited by the thin $\beta$ lamellae during the tensile deformation. The special characteristics of the S-EM reduce the stress concentration at the interface, and the crack initiation probability in the blurry semi- $\alpha_{p} / \beta_{\text {trans }}$ interface decreased compared to the distinct $\alpha_{p} / \beta_{\text {trans }}$ interface in a conventional equiaxed microstructure (EM). Moreover, the ultimate tensile strength of the S-EM is higher than that of the EM with a slight loss of plasticity.
\end{abstract}

Keywords: TA19 titanium alloy; semi-equiaxed microstructure; in situ SEM test; deformation behavior; mechanical properties

\section{Introduction}

TA19 titanium alloy is a near alpha titanium alloy that is widely utilized in key structural components of aero-engines (e.g., compressor disks, blades, and casings) [1] due to its high strength to weight ratio, high temperature resistance, and corrosion resistance [2-4]. The mechanical properties of titanium alloys are largely influenced by the microstructural characteristics, such as the morphology and volume fraction of the $\alpha$ and $\beta$ phases, and the grain size $[5,6]$. In particular, the interface characteristics between the $\alpha$ phase and $\beta$ phase are fundamentally of significance during crack initiation and propagation [7-9]. For example, most of the cracks (approximately 50\%) of TC21 titanium alloy (Ti-6Al-2Sn-2Zr$3 \mathrm{Mo}-1 \mathrm{Cr}-2 \mathrm{Nb}-0.1 \mathrm{Si}$ ) generally initiate at the shear bands of the primary $\alpha$ lath, cracks also initiate at the $\alpha_{\mathrm{p}} / \beta_{\text {trans }}$ interface (approximately 23\%) and $\alpha_{\mathrm{s}} / \beta$ interface (approximately $27 \%$ ) during the tensile loading [10]. In addition, when the size of $\alpha_{\mathrm{s}}$ is approximately $0.1 \mu \mathrm{m}$, cracks will initiate at the $\alpha_{\mathrm{p}} / \beta$ interface and $\alpha_{\mathrm{p}} / \beta_{\text {trans }}$ interface. When the size of $\alpha_{\mathrm{s}}$ is approximately $0.5 \mu \mathrm{m}$, cracks also initiate at the $\alpha_{\mathrm{s}} / \beta_{\mathrm{r}}$ interface [11] $\left(\alpha_{\mathrm{p}}\right.$ : equiaxed primary $\alpha$ phase; $\alpha_{\mathrm{s}}$ : lamellar secondary $\alpha$ phase; $\beta_{\text {trans }}$ : transformed $\beta$ microstructure; $\beta_{\mathrm{r}}$ : remnant $\beta$ phase). The phase interface in titanium alloy can effectively prevent dislocation movement and improve strength [7]. However, inconsistencies between the stress and strain easily occur at the interface during loading, resulting in stress concentration at the phase interface due to the differences in the physical, mechanical properties, and grain 
orientation between the $\alpha$ phase and $\beta$ phase. Therefore, the phase interface is the preferred site for crack nucleation and propagation under tensile [10] or fatigue loading [12], which is detrimental to the mechanical properties of the alloy $[13,14]$. The stress concentration caused by dislocation pile-up can be reduced by refining the $\alpha$ phase in titanium alloy [15], but the stress concentration at the interface has not been effectively alleviated.

Different from the above-mentioned microstructural interface, the ghost $\alpha$ phases with blurry $\alpha_{p} / \beta_{\text {trans }}$ interface characteristics in the welding heat-affected zone (HAZ) of Ti6246 alloy have been reported [16,17]. The ghost $\alpha$ phases are the original equiaxed $\alpha$ phase of the base metal, which exceeds the $\beta$ phase transition temperature during welding, but the temperature and time are not sufficient to reach chemical equilibrium [17]. Xu et al. [18] also revealed that Ti6242 alloy flash welded joint obtains high ductility that is equivalent to the matrix and extra strain hardening due to the presence of the semi-equiaxed microstructure (similar to the ghost $\alpha$ phases) in the HAZ, but the specific effect of a pure semi-equiaxed microstructure on the mechanical properties is still unclear. Furthermore, Liang et al. [19] prepared the semi-equiaxed microstructure in TA19 titanium alloy by simulating the temperature field of the welding heat-affected zone. The tensile strength of the sample of the semi-equiaxed microstructure was $1219 \mathrm{MPa}$, which was $15 \%$ higher than that of the asreceived material. However, limited efforts have been made to study the deformation and fracture characteristics of the semi-equiaxed microstructure. These studies have confirmed that the semi-equiaxed microstructure has particular microstructure and mechanical properties. Original $\alpha_{p} / \beta_{\text {trans }}$ interfaces disappear in the semi-equiaxed microstructure, and whether this interface's characteristics show special mechanical properties and deformation behavior requires further exploration.

In this study, the TA19 titanium alloy sample was rapidly heated $\left(>100{ }^{\circ} \mathrm{C} / \mathrm{s}\right)$ to $\beta$ phase field $\left(T>T_{\beta}\right)$ and held for $35 \mathrm{~s}$, thereby inhibiting the diffusion of alloying elements, and finally, a pure semi-equiaxed microstructure was prepared. An in situ tensile test was used to explore the deformation, crack initiation, and propagation characteristics of the equiaxed microstructure and semi-equiaxed microstructure. These results were combined with the results of room temperature tensile tests to further study the differences in the tensile properties caused by the two types of microstructures. The study will provide guidance for tailoring the microstructure and enriching the mechanism of the strengthening and toughening titanium alloys.

\section{Experimental Procedures}

In this work, a TA19 bar was supplied after rolling at the $\alpha+\beta$ field to obtain a plate about $65 \times 35 \times 170 \mathrm{~mm}^{3}$; then, it was tempered in the $\alpha+\beta$ field. The chemical composition of the TA19 bar is shown in Table 1. The microstructure consists of an equiaxed primary $\alpha$ phase $\left(\alpha_{p}\right)$ and transformed $\beta$ microstructure $\left(\beta_{\text {trans }}\right)$, and the transformed $\beta$ microstructure contains a lamellar secondary $\alpha$ phase $\left(\alpha_{\mathrm{s}}\right)$ and remnant $\beta$ phase $\left(\beta_{\mathrm{r}}\right)$, as presented in Figure 1 . The $\alpha / \beta$ phase transition temperature is approximately $1006{ }^{\circ} \mathrm{C}$ based on thermal analysis using a DIL805A/D phase analyzer (Netzsch, Selb, Germany). Two heat treatment modes were chosen to obtain the equiaxed microstructure (EM) and semi-equiaxed microstructure (S-EM), ensuring that the volume fraction of the equiaxed $\alpha_{p}$ phase, the length and thickness of the $\alpha_{s}$ lamellae are almost same in the two types of microstructures: (1) $970{ }^{\circ} \mathrm{C} / 1 \mathrm{~h}$, air cooling (AC) (for EM) and (2) $1015^{\circ} \mathrm{C} / 35 \mathrm{~s}$, with a cooling rate of $20^{\circ} \mathrm{C} / \mathrm{s}$ (for S-EM). For optical microscopy (OM, Leica DMI5000M) (Leica, Wetzlar, Germany) and scanning electron microscopy (SEM, SUPRA40) (Carl Zeiss AG, Jena, Germany) observations, samples were ground and mechanically polished by a standard metallographic procedure (for more details, please see Ref. [20]), and they were etched with Kroll's reagent solution $\left(\mathrm{V}(\mathrm{HF}): \mathrm{V}\left(\mathrm{HNO}_{3}\right): \mathrm{V}\left(\mathrm{H}_{2} \mathrm{O}\right)=1: 3: 7\right)$. Moreover, microstructural parameters were counted by an Image-Pro Plus image analysis system. X-ray diffraction (XRD) analysis was carried out on a D8 Advance $\mathrm{X}$-ray diffractometer with a $\mathrm{Cu} \mathrm{K} \alpha$ source $(40 \mathrm{kV}, 200 \mathrm{~mA})$ in the $\theta-2 \theta$ model. Electron back-scattered diffraction (EBSD) images were acquired to determine the misorientation distribution of the grains. In situ observation 
was performed with a SUPRA 40 scanning electron microscope at room temperature during the tensile deformation. The surfaces of the specimens were mechanically polished and strained with a crosshead speed of $0.1 \mu \mathrm{m} / \mathrm{s}$. Room temperature tensile tests were carried out as standard E8/E8M Test Methods [21] on a tensile instrument (MTS 810) at a constant cross-head speed of $0.5 \mathrm{~mm} / \mathrm{min}$. Three samples with gauge dimensions of $44 \times 9 \times 2 \mathrm{~mm}^{3}$ (Figure 2) were tested to confirm the validity of the test results, and the fracture surface morphology was observed by SEM. An FEI Talos F200X field emission transmission electron microscope (TEM) (FEI, Hillsboro, OR, USA) was used to observe the microstructure after tensile fracture, thereby revealing the deformation mechanism.

Table 1. Chemical components of the material (wt \%).

\begin{tabular}{ccccccc}
\hline A1 & Sn & Zr & Mo & W & Si & Ti \\
\hline 6.61 & 1.75 & 4.12 & 1.91 & 0.32 & 0.10 & Bal. \\
\hline
\end{tabular}

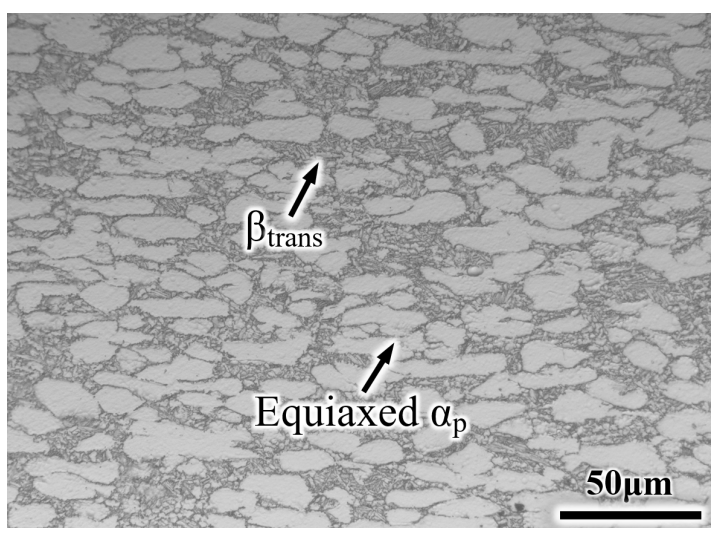

Figure 1. Initial microstructure of TA19 titanium alloy.

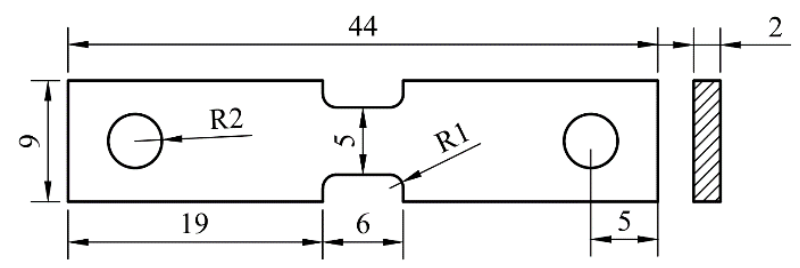

Figure 2. Specimen dimensions used for tensile tests.

\section{Results and Discussion}

\subsection{Microstructural Characteristics}

Figure 3 shows the optical micrographs and SEM micrographs of the EM and S-EM. The morphology of the EM is almost consistent with the initial microstructure, but the volume fraction of the equiaxed $\alpha_{\mathrm{p}}$ phase and $\alpha_{\mathrm{s}}$ lamellae decrease (Figure 3a), which is due to allotropic transformation $(\alpha \rightarrow \beta)$ after heating to the $\alpha / \beta$ phase region. The formation of the S-EM is due to the inhomogeneous diffusion of elemental Mo in the $\beta$ matrix into the equiaxed $\alpha_{p}$ phase when the specimens are kept above the $T_{\beta}$ temperature for a short time, and in the cooling process, the thin $\beta$ lamellae grow through the equiaxed $\alpha_{p}$ phase [19]. A large amount of the equiaxed $\alpha_{p}$ phases remain in the S-EM because after a transient $\beta$ phase treatment, only the micro-zone adjacent to the original equiaxed $\alpha_{p}$ phase boundary is transformed into the $\beta$ phase. In this work, a relatively slow cooling rate was used to obtain the S-EM with obvious microstructural morphology, resulting in some $\alpha$ phases continuous precipitating along the grain boundaries (GB $\alpha$ ) (Figure $3 b$ ). Figure $3 c, d$ show SEM images of the EM and S-EM, respectively. Notably, there is a distinct $\alpha_{\mathrm{p}} / \beta_{\text {trans }}$ interface in the EM (Figure 3c). However, the distinct $\alpha_{p} / \beta_{\text {trans }}$ interface mainly disappears 
in the S-EM, the thin $\beta$ lamellae grow through the equiaxed $\alpha_{\mathrm{p}}$ phase and exhibits a blurry interface (Figure $3 \mathrm{~d}$ ). The thickness of the thin $\beta$ lamellae gradually decreases and finally disappears within the equiaxed $\alpha_{p}$ phase, as shown in the inset TEM image. The equiaxed $\alpha_{p}$ phase is grew through by the thin $\beta$ lamellae in the S-EM, which is defined as the semi-equiaxed $\alpha_{p}$ phase (semi- $\alpha_{p}$ ) in this paper. The microstructural feature results of the EM and S-EM are presented in Table 2.
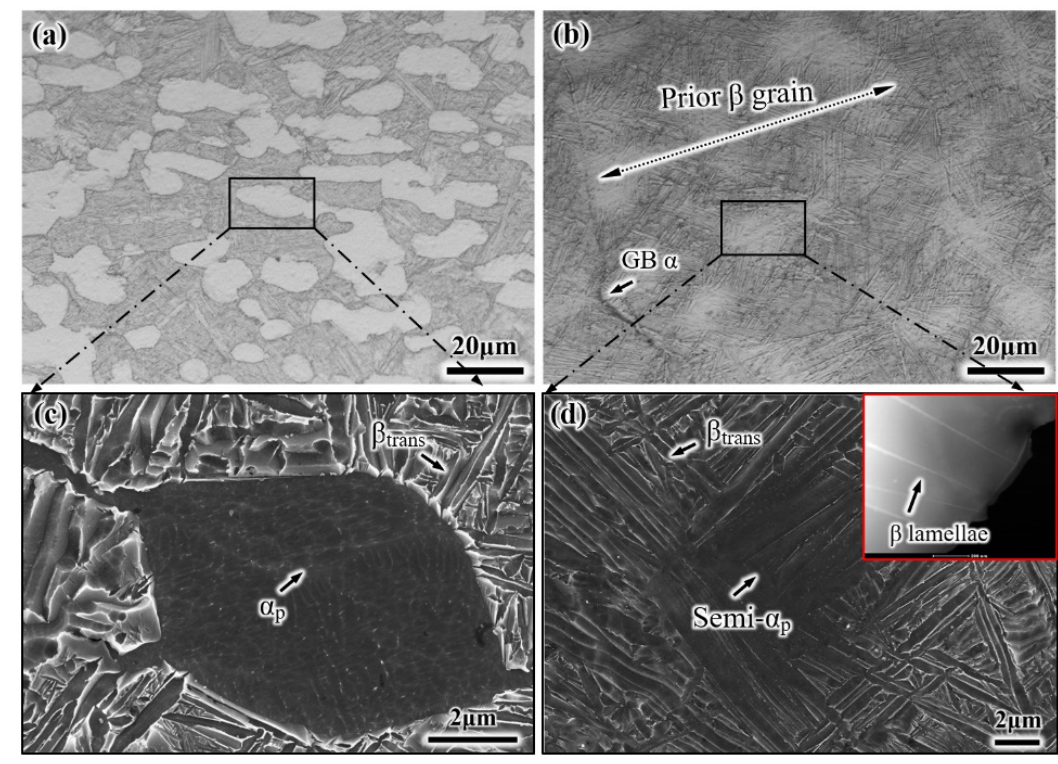

Figure 3. Typical microstructure after heat treatment: $(\mathbf{a}, \mathbf{c})$ EM and $(\mathbf{b}, \mathbf{d})$ S-EM.

Table 2. Summary of the constituent phase parameters for the EM and S-EM.

\begin{tabular}{ccccccc}
\hline Microstructure & $\begin{array}{c}\boldsymbol{\alpha}_{\mathbf{p}} \\
(\mathbf{v o l} \%)\end{array}$ & $\begin{array}{c}\alpha_{\mathbf{p}} \text { Diameter } \\
(\boldsymbol{\mu m})\end{array}$ & $\begin{array}{c}\boldsymbol{\alpha}_{\mathbf{s}} \text { Length } \\
(\boldsymbol{\mu} \mathbf{m})\end{array}$ & $\begin{array}{c}\boldsymbol{\alpha}_{\mathbf{s}} \text { Width } \\
(\mathbf{n m})\end{array}$ & $\begin{array}{c}\text { GB } \boldsymbol{\alpha} \\
(\mathbf{v o l} \%)\end{array}$ & $\begin{array}{c}\text { GB } \boldsymbol{\alpha} \text { Width } \\
(\mathbf{n m})\end{array}$ \\
\hline EM & $42 \pm 2$ & $12 \pm 1$ & $10 \pm 1$ & $400 \pm 20$ & 0.3 & $420 \pm 30$ \\
\hline S-EM & $41 \pm 2$ & $13 \pm 1$ & $11 \pm 1$ & $410 \pm 20$ & 1.2 & $850 \pm 30$ \\
\hline
\end{tabular}

Figure 4 shows the XRD patterns for the initial microstructure, the EM and S-EM of TA19 titanium alloy. The phase constitutions of the three samples are the $\alpha$ phase and $\beta$ phase, and the intensity distribution of the diffraction peak of the $\alpha$ phase and $\beta$ phase is similar. In the XRD patterns, $\alpha_{(101)}$ is the strongest among all of the diffraction peaks of both $\alpha$ and $\beta$ phases.

To explore the effect of the phase transition on the misorientation distribution of grains in the EM and S-EM, EBSD analysis of the microscopic regions, including the equiaxed $\alpha_{p}$ phase and the semi-equiaxed $\alpha_{p}$ phase of the two samples, were performed. The step size is $0.2 \mu \mathrm{m}$, as shown in Figure 5. For the EM, the equiaxed $\alpha_{\mathrm{p}}$ maintains the same orientation relationship, and the fine $\alpha / \beta$ lamellae in the $\beta_{\text {trans }}$ microstructure exhibit different orientation relationships (Figure 5a). For the S-EM, the semi-equiaxed $\alpha_{\mathrm{p}}$ phase is formed after the phase transition of the original equiaxed $\alpha_{p}$ phase, which exhibits different orientation relationships. This phenomenon is different from the same orientation relationships of the equiaxed $\alpha_{p}$ phase in the EM. The $\beta_{\text {trans }}$ microstructure in the S-EM is similar to the EM and shows multiple orientation (Figure $5 b$ ). 


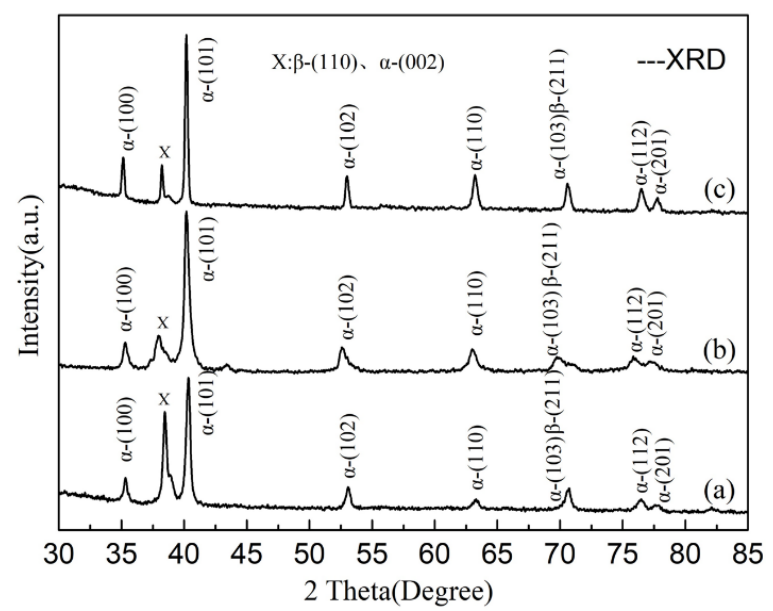

Figure 4. XRD patterns of the TA19 titanium alloy: (a) initial microstructure, (b) EM, and (c) S-EM.
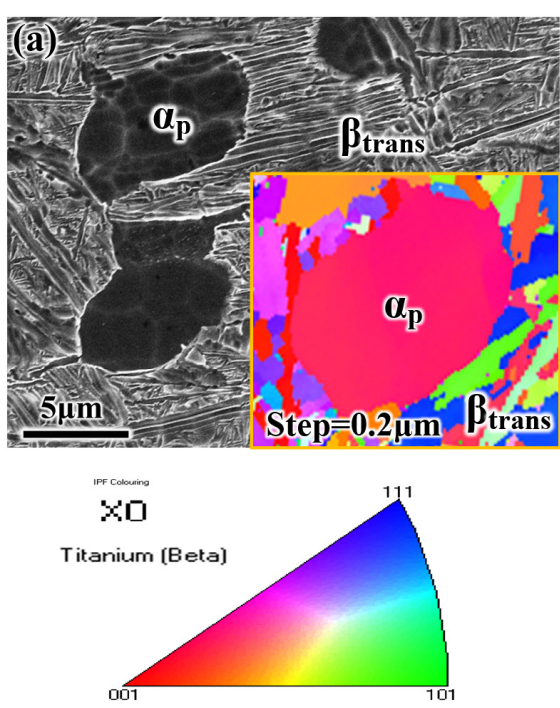
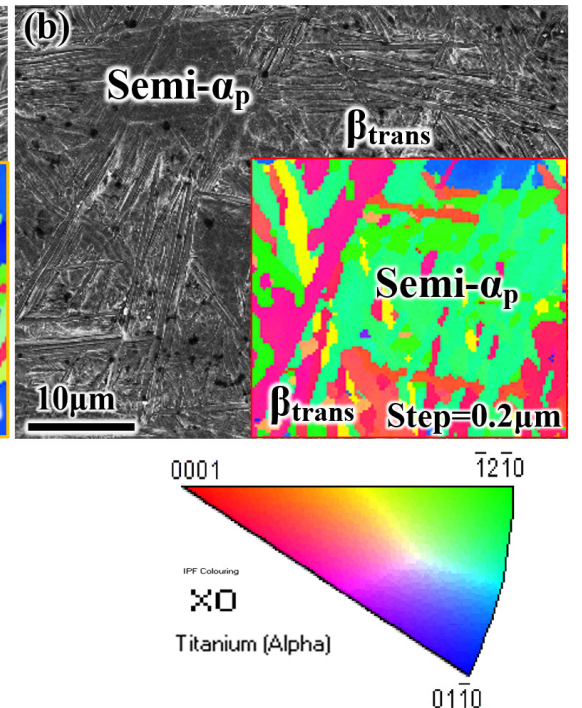

Figure 5. EBSD results (IPF maps) of the TA19 titanium alloy: (a) EM and (b) S-EM.

\subsection{Research on the Deformation Behavior}

The above description of the microstructural characteristics illustrates that the S-EM has special interface microstructural characteristics compared with the EM. An in situ tensile test is designed, as it is an effective method for comparing the deformation behavior of the two types of microstructures. During the in situ tensile process, at some strain points, the test was interrupted, and the SEM images were captured. The interval between adjacent strain points is approximately two minutes. The typical Engineering stress-strain curves of the two samples in the in situ tensile test performed at room temperature are shown in Figure 6. Moreover, the representative strain points of $6 \%, 8.3 \%, 12 \%$, and $14 \%$ (corresponding to the letters $A_{1}\left(A_{2}\right), B_{1}\left(B_{2}\right), C_{1}\left(C_{2}\right)$, and $D_{1}\left(D_{2}\right)$, respectively) are selected to analyze the deformation characteristics of EM and S-EM.

Figure 7 shows the actual deformation behavior of the EM in the in situ tensile test, and the tensile direction of the SEM images is parallel to the horizontal direction. When the strain is $6 \%$ (corresponds to the letter $A_{1}$ on the curve in Figure 6), the equiaxed $\alpha_{p}$ phase deformation occurs first, and a small number of slip bands within the equiaxed $\alpha_{p}$ phase (numbers 1 and 2) are observed (Figure 7a). With a further increase in strain to $8.3 \%$ (letter $B_{1}$ ), more slip bands are observed in the equiaxed $\alpha_{p}$ phase of numbers 1 and 2 (Figure $7 b$ ), indicating that the equiaxed $\alpha_{\mathrm{p}}$ phases have good deformation capacity. However, there are no slip bands in the number 3 equiaxed $\alpha_{p}$ phase, and the orientation of this equiaxed 
$\alpha_{\mathrm{p}}$ phase might not be favorable enough to initiate deformation at an early deformation stage. In addition, a large number of slip bands are hindered by the interface between the number 4 equiaxed $\alpha_{p}$ phase and $\beta_{\text {trans }}$ microstructure, it causes local stress concentration, and a crack initiates at the $\alpha_{\mathrm{p}} / \beta_{\text {trans }}$ interface. The crack also initiates at the coarsening $\alpha_{\mathrm{s}}$ lamella perpendicular to the tensile direction duo to the lamella being subjected to greater tensile stress. At a strain of $12 \%$ (letter $C_{1}$ ), the crack propagates rapidly from one end along the direction of the $\alpha_{s}$ lamellae and from the other end along the slip band within the equiaxed $\alpha_{p}$ phase, forming a low-energy channel for crack propagation. The cross slip of the number 4 equiaxed $\alpha_{p}$ phase occurs, and the direction of crack propagation changes. Moreover, a crack also initiates in the number 5 equiaxed $\alpha_{\mathrm{p}}$ phase (Figure $7 \mathrm{c}$ ). When the strain is further increased to $14 \%$ (letter $\mathrm{D}_{1}$ ), the microstructure is severely deformed, and the length of the number 4 equiaxed $\alpha_{p}$ phase is increased by approximately $47 \%$ in the tensile direction. Moreover, the entire crack width is extended to $8 \mu \mathrm{m}$, which will lead to fracture failure of the alloy (Figure 7d). Notably, cracks also initiate at the other $\alpha_{\mathrm{p}} / \beta_{\text {trans }}$ interface when the strain is $11.6 \%$ and $14.7 \%$, as shown in Figure 8.

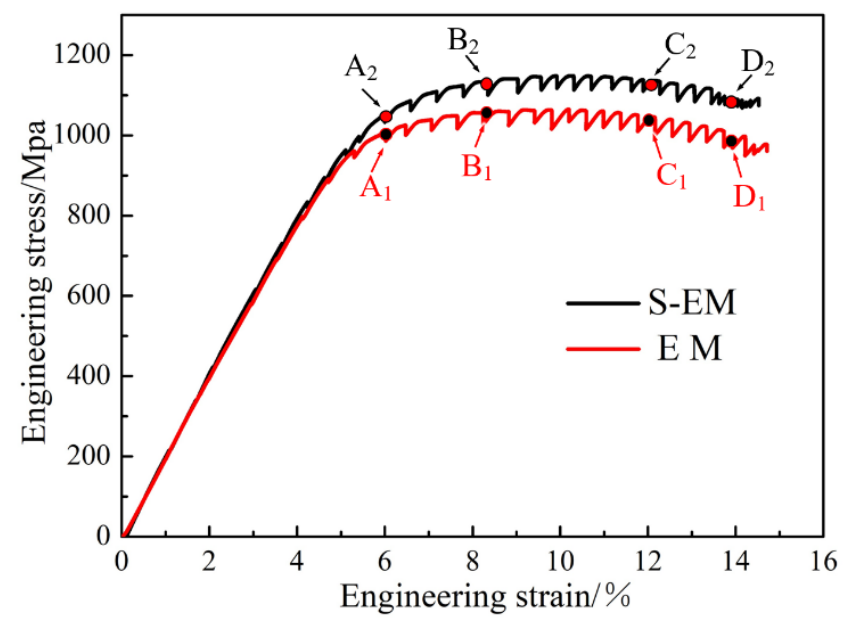

Figure 6. Engineering stress-strain curves for the EM and S-EM after the in situ SEM tensile test. The letters $A_{1}\left(A_{2}\right), B_{1}\left(B_{2}\right), C_{1}\left(C_{2}\right)$, and $D_{1}\left(D_{2}\right)$ indicate the points at which the test was interrupted for imaging.

For the S-EM sample, no slip bands were found in the semi-equiaxed $\alpha_{p}$ phase (numbers 1,2, and 3) when the strain is 6\% (letter $A_{2}$ ), as shown in Figure 9a. Before the strain reaches $14 \%$ (letter $\mathrm{D}_{2}$ ), the microstructural characteristics of the S-EM have not changed significantly, so SEM images with strain of $12 \%$ (letter $C_{2}$ ) are not considered. Compared to the EM, there is no obvious slip bands and cracks existing in the semiequiaxed $\alpha_{\mathrm{p}}$ phase of the S-EM when the strain is 14\% (Figure 9c). The higher magnification image of Figure $9 \mathrm{c}$ shows that only a few and shorter slip bands occur between the thin $\beta$ lamellae in the semi-equiaxed $\alpha_{p}$ phase (Figure 9d). These results reveal that the thin $\beta$ lamellae inhibit the formation of dense slip bands in the semi-equiaxed $\alpha_{p}$; thereby, dislocations do not easily pile up at the blurry interface between the semi-equiaxed $\alpha_{p}$ phase and $\beta_{\text {trans }}$ microstructure in a large amount. The bending and tearing deformation of the thin $\beta$ lamellae within the semi-equiaxed $\alpha_{\mathrm{p}}$ phase are observed (Figure 9e). In addition, the transfer of short slip bands across the thin $\beta$ lamellae was observed in the semi-equiaxed $\alpha_{p}$ phase, resulting in zig-zag ledges, as shown in Figure 9f. This indicates that the thin $\beta$ lamellae have a slight effect on hindering the movement of dislocations and slip transfer. 


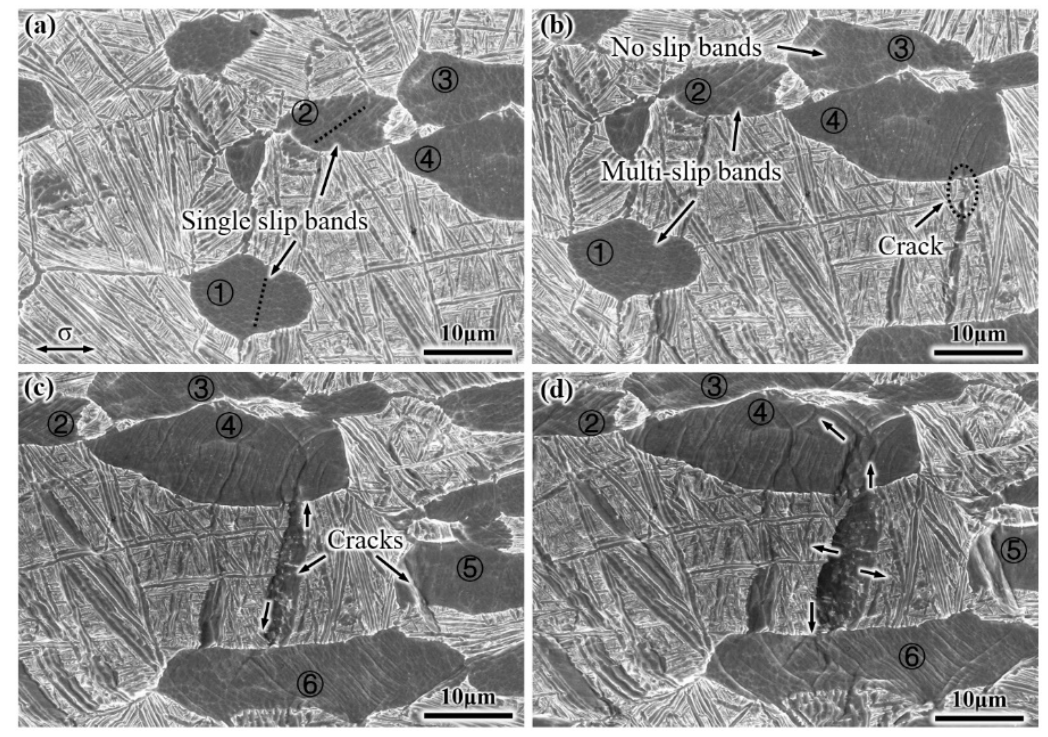

Figure 7. Microstructural characteristics of the EM under tensile deformation at different strain: (a) $6 \%$, (b) $8.3 \%$, (c) $12 \%$, and (d) $14 \%$. (The different equiaxed $\alpha_{\mathrm{p}}$ phases in the EM are marked with (1), (2), (3), (4), (5) and (6).
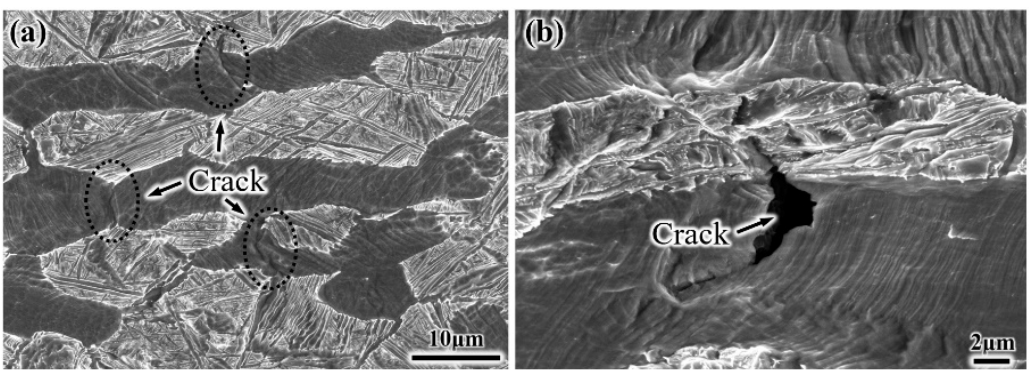

Figure 8. Cracks initiate at the $\alpha_{\mathrm{p}} / \beta_{\text {trans }}$ interface of the EM at different strain: (a) $11.6 \%$ and (b) $14.7 \%$.

Titanium alloys exhibit many deformation behaviors, and the strain modes include planar slip, dislocation tangling, and twinning [22]. Generally, the activation of a slip system requires that a high resolved shear stress on the slip system exceeds its critical resolved shear stress (CRSS) [23]. When the resolved shear stress is higher than the critical resolved shear stress, planar slip occurs, which is the main deformation mode. Additionally, the deformation of hardly oriented grains is accompanied by dislocation tangling. During the tensile deformation, the number of slip bands and the distribution of dislocations in each grain depend on the local strain.

Figure 10 shows TEM micrographs of the deformation microstructure of the EM sample after tensile fracture. The observation area is approximately $1 \mathrm{~mm}$ away from the fracture. As shown in Figure 10a, dislocation tangling occurs at the $\alpha_{p} / \beta_{\text {trans }}$ interface, which is the result of dislocation slip being hindered at the $\alpha_{p} / \beta_{\text {trans }}$ interface. A large number of slip bands are arranged along a specific crystal plane, which is observed in the local higher magnification images of Figure 10a. The distance between the slip bands is approximately $70 \mathrm{~nm}$. From the diffraction pattern of the selected area, these slip bands belong to the $\{011(-) 0\}$ prismatic slip bands (Figure 10b). Slip systems with high Schmid factor values and low CRSS (basal <a $>$ and prismatic <a $>$ slip) can be preferentially activated under tensile stress at room temperature, and prismatic $<a>$ slip is more easily activated than basal $<$ a $>\operatorname{slip}[10]$. The above phenomena indicate that equiaxed $\alpha_{\mathrm{p}}$ phase plays an important role in accommodating the plastic deformation of the alloy, and this result is consistent with Ref [24]. The equiaxed $\alpha_{p}$ phase does not maintain the Burgess orientation relationship (BOR) with the adjacent $\beta$ phase, which greatly restricts slip 
transmission across the $\alpha_{p} / \beta_{\text {trans }}$ interface [25]. So, the slip bands do not pass through the equiaxed $\alpha_{\mathrm{p}}$ phase to the $\beta_{\text {trans }}$ microstructure (Figure 10b), resulting in the stress concentration at the $\alpha_{p} / \beta_{\text {trans }}$ interface. Meanwhile, it can be seen from Figure 10c that the remnant $\beta_{\mathrm{r}}$ phase is fractured in shear due to severe local deformation, and the short slips are observed in the coarsening $\alpha_{\mathrm{s}}$ lamellae, which are also recorded as shear slip bands by Ref. [26]. Moreover, there is high density dislocation tangling in the coarsening $\alpha_{s}$ lamellae, which occurs because the slip motion in $\alpha_{s}$ lamellae is hindered at the $\alpha_{s} / \beta_{r}$ interface (Figure 10d).
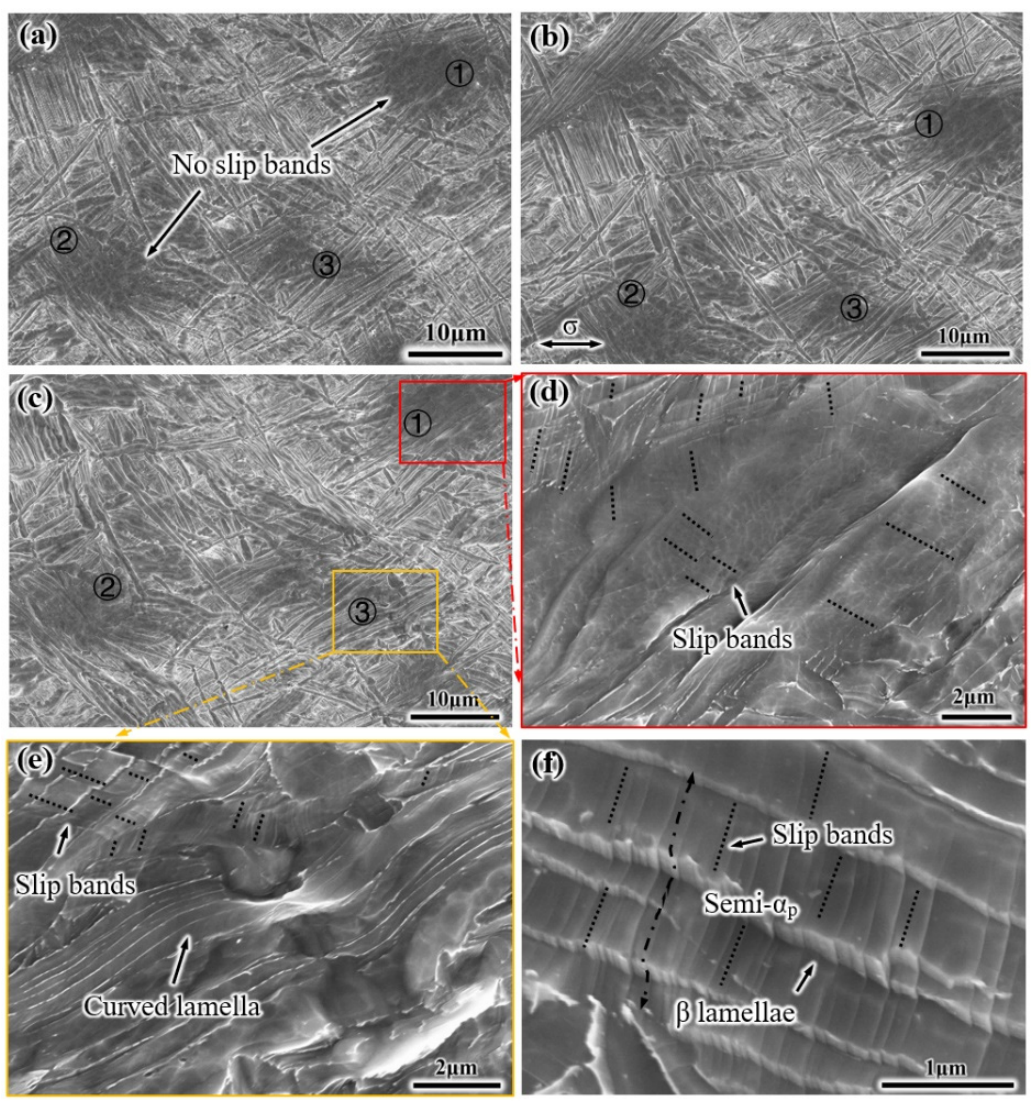

Figure 9. Microstructural characteristics of the S-EM under tensile deformation at different strain: (a) $6 \%$, (b) $8.3 \%$, and (c-f) $14 \%$. (The different semi-equiaxed $\alpha_{p}$ phases in the S-EM are marked with (1), (2) and (3).

Figure 11 shows the TEM micrographs of the deformation microstructure of the S-EM sample after tensile fracture, which is consistent with the observation area of the EM. The thickness of the thin $\beta$ lamellae within the semi-equiaxed $\alpha_{\mathrm{p}}$ phase in the S-EM is approximately $20 \mathrm{~nm}$, which is slightly smaller than that of the remnant $\beta_{\mathrm{r}}$ phase. Different from a large number of slip bands in the equiaxed $\alpha_{\mathrm{p}}$ phase of the EM, short slip bands and dislocation tangling are produced between the thin $\beta$ lamellae in the semi-equiaxed $\alpha_{p}$ phase of the S-EM (Figure 11a); this is the result of dislocation slip being hindered by the thin $\beta$ lamellae. The phenomenon of dislocation tangling between the thin $\beta$ lamellae in the semi-equiaxed $\alpha_{\mathrm{p}}$ phase is more obvious in the local higher magnification images (Figure 11b). The diffraction pattern shows that the slip bands between the thin $\beta$ lamellae in the semi-equiaxed $\alpha_{p}$ belong to the $\{011(-) 0\}$ prismatic slip bands (Figure 11c), which is consistent with the deformation characteristics in the equiaxed $\alpha_{p}$ phase of the EM. 

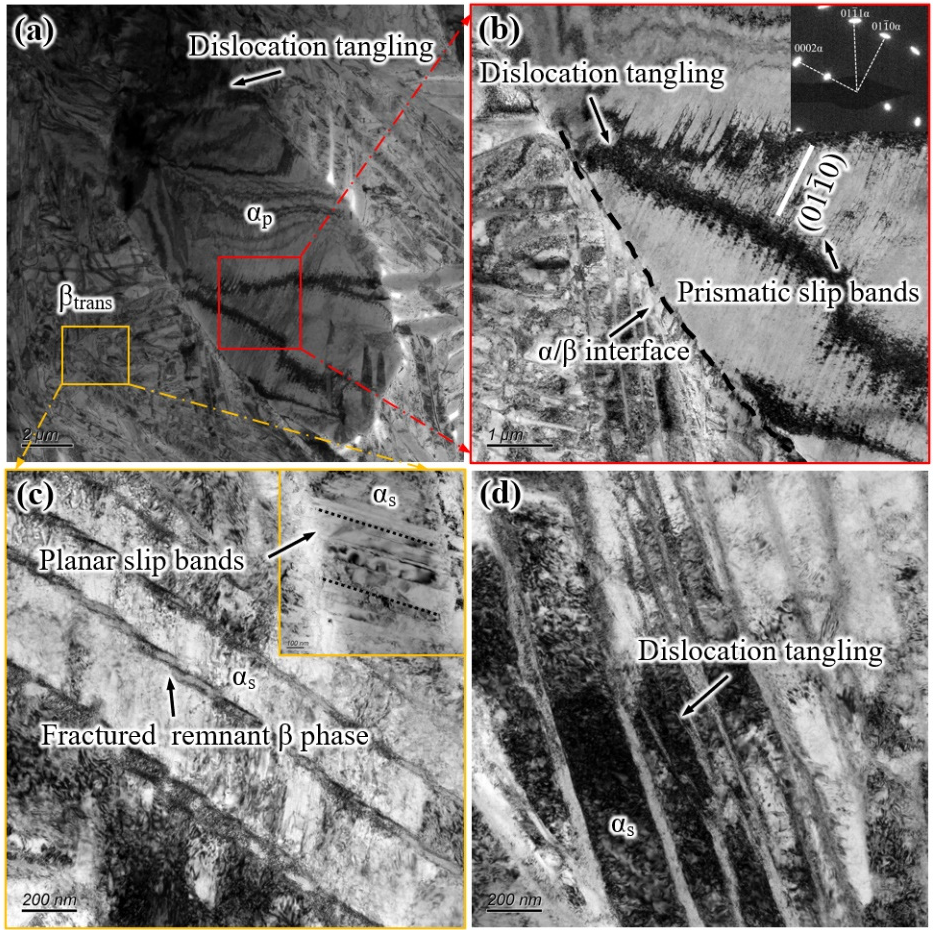

Figure 10. Deformation behavior of the tensile specimen with the EM: (a) dislocation tangling in equiaxed $\alpha_{\mathrm{p}}$ phase, (b) prismatic slip bands in equiaxed $\alpha_{\mathrm{p}}$ phase, (c) fractured $\beta_{\mathrm{r}}$ lamellae, and (d) dislocation tangling in $\alpha_{\mathrm{s}}$ lamellae.
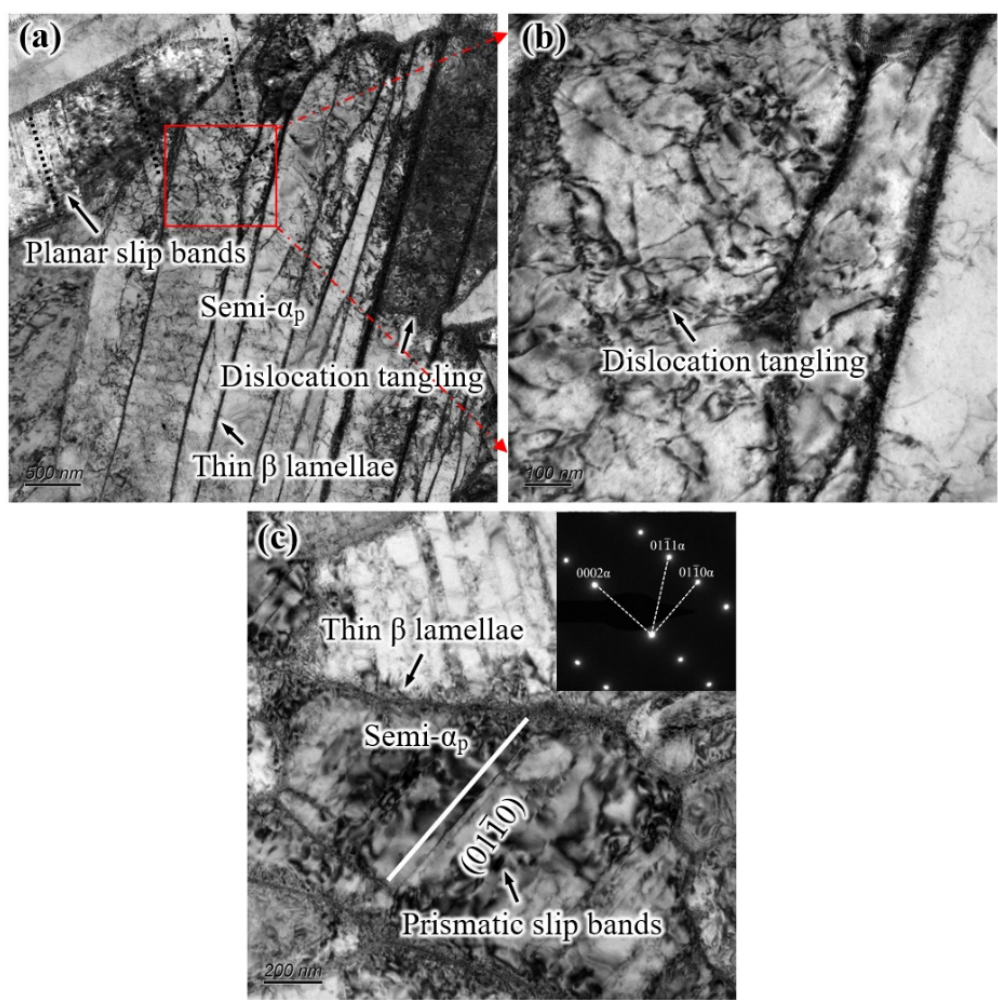

Figure 11. Deformation behavior of the tensile specimen with the S-EM: $(\mathbf{a}, \mathbf{b})$ dislocation tangling and planar slip bands between the thin $\beta$ lamellae of the semi-equiaxed $\alpha_{\mathrm{p}}$ phase and (c) prismatic slip bands between the thin $\beta$ lamellae of the semi-equiaxed $\alpha_{\mathrm{p}}$ phase. 


\subsection{Tensile Properties and Fracture Characteristics}

For titanium alloys, preventing dislocation slip is the most significant strengthening mechanism, in which grain boundaries and phase interfaces act as barriers to reduce the effective slip length, i.e., the Hall-Petch effect $[27,28]$. The typical engineering tensile stress-strain curves of the TA19 titanium alloy with the EM and S-EM at room temperature are shown in Figure 12. Furthermore, the room temperature tensile properties of EM and S-EM are summarized in Table 3. It is obvious from Figure 12 and Table 3 that the yield strength (YS) and the ultimate tensile strength (UTS) of S-EM are higher $38 \mathrm{MPa}$ and $46 \mathrm{MPa}$ than those of EM, respectively. On the contrary, the elongation (El) and reduction in area (RA) of S-EM are slightly lower than that of EM. The characteristics of the $\beta_{\text {trans }}$ microstructure in the EM and S-EM are basically the same. Therefore, the difference in the tensile properties of EM and S-EM mainly depends on the distinct microstructural characteristics of the equiaxed $\alpha_{p}$ phase and semi-equiaxed $\alpha_{p}$ phase. The thin $\beta$ lamellae grow through the equiaxed $\alpha_{p}$ phase in the S-EM, which hinders the slip of dislocations and reduces the effective slip length in semi-equiaxed $\alpha_{p}$ phase, and the strength of the S-EM is improved.

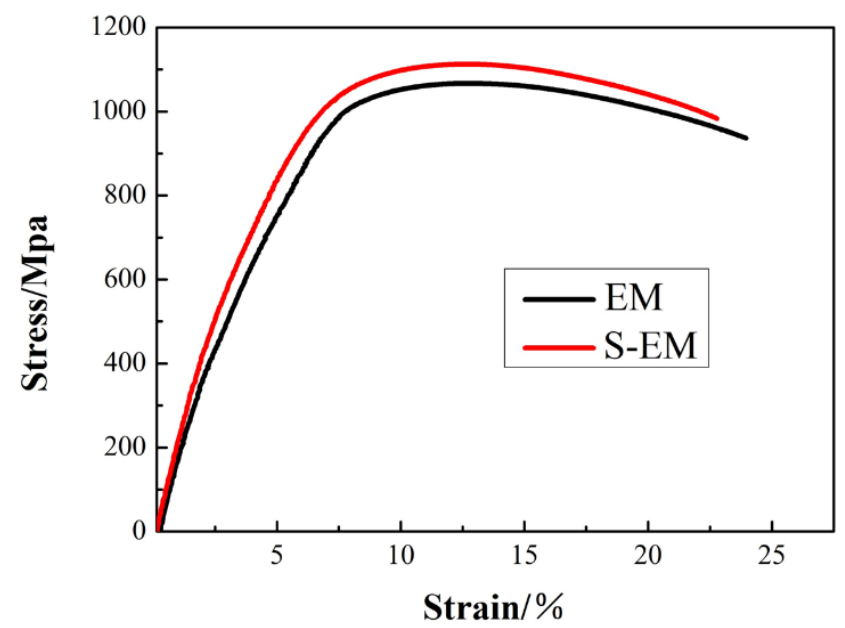

Figure 12. Typical engineering stress-strain curves of the EM and S-EM.

Table 3. Tensile properties of EM and S-EM at room temperature.

\begin{tabular}{ccccc}
\hline Microstructure & YS/Mpa & UTS/Mpa & El/\% & RA/\% \\
\hline EM & 984 & 1067 & 23.9 & 32.9 \\
S-EM & 1022 & 1113 & 22.8 & 30.8 \\
\hline
\end{tabular}

The tensile fracture surface morphology of the EM and S-EM was analyzed to further comprehend the influence of the microstructure on the properties of the TA19 titanium alloy, as displayed in Figure 13. From the low magnification photography of the fracture surface, the shearing tip and dimple zone occur in the EM sample, and the necking characteristics are relatively obvious (Figure 13a), which is a typical feature of high plasticity. In addition, the shearing tip and dimple zone can also be observed in the macroscopic fracture surface of the S-EM, but the area of the shearing tip is slightly smaller than that of the EM, and the necking characteristic is less obvious (Figure 13b). The high magnification photography of the fracture surface shows that both the EM and S-EM tensile specimens fail in a mixed fracture mode. In the fracture surface with EM, the failure induced by dimple nucleation and coalescence along the $\alpha_{\mathrm{p}} / \beta_{\text {trans }}$ interfaces is observed, and there are tearing ridges between the dimples. The cleavage facets are relatively smooth, which is attributed to the expansion of the cracks along the equiaxed $\alpha_{p}$ inner slip bands or the $\alpha_{p} / \beta_{\text {trans }}$ interface (Figure 13c). The dimples in the S-EM samples are small and shallow. The surfaces of the dimples are rough, and there are many small microvoids, which may be the characteristics 
left by the fracture of the thin $\beta$ lamellae in the semi-equiaxed $\alpha_{p}$ phase. Furthermore, the proportion of cleavage facets (highlighted by the red arrow) increases, and traces of fracture along the grain boundary (highlighted by the yellow arrow) are found (Figure 13d).

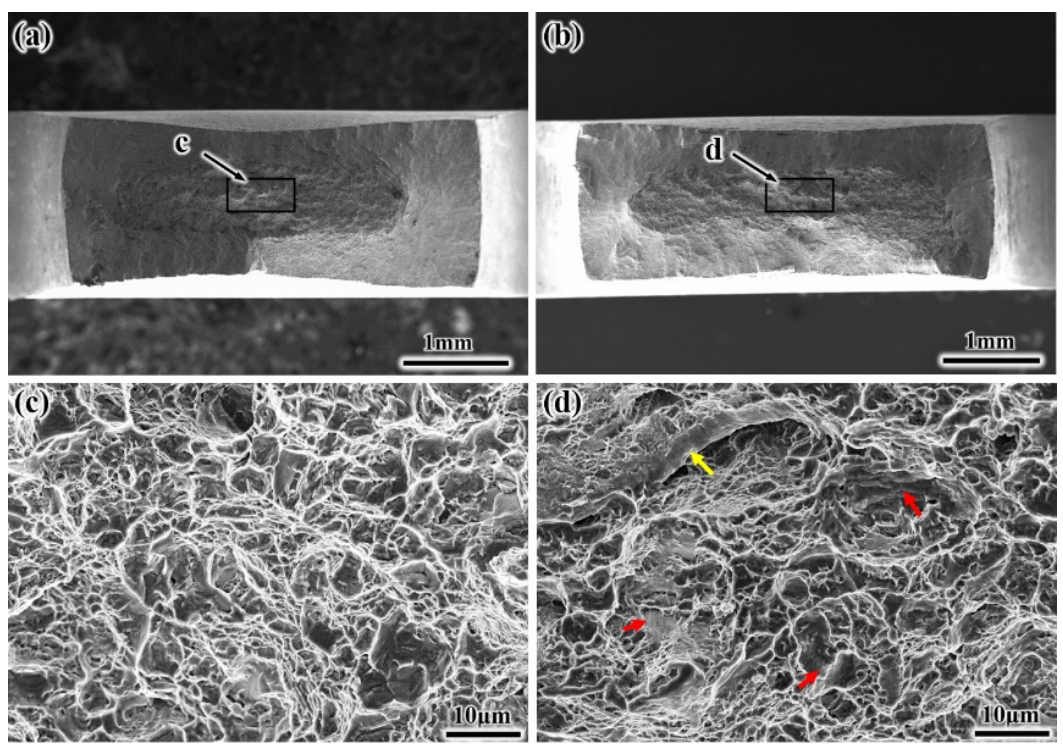

Figure 13. Fractographs of TA19 titanium alloy specimens with the EM and S-EM after tensile deformation showing a mixed failure mode: $(\mathbf{a}, \mathbf{c})$ EM and $(\mathbf{b}, \mathbf{d})$ S-EM.

Combined with the in situ tensile test, it is found that the approximately $3 \mu \mathrm{m}$ crack first initiates at GB $\alpha$ of the S-EM when the strain is $11.8 \%$ (Figure 14). In contrast, the crack first initiates at the $\alpha_{p} / \beta_{\text {trans }}$ interface in the EM when the strain is $8.3 \%$. Therefore, some GB $\alpha$ precipitates on the $\beta$ grain boundary in the S-EM, which is an important factor that causes early fracture and ultimately leads to the decrease in plasticity [29].
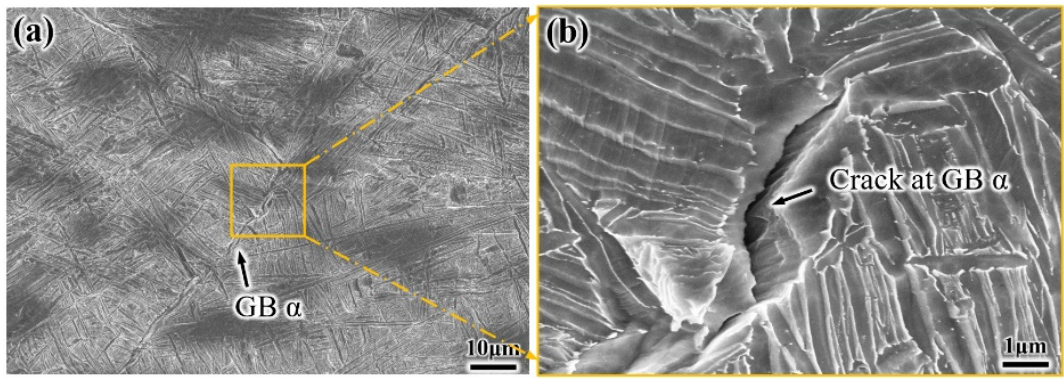

Figure 14. (a) Cracks preferentially initiate at GB $\alpha$ of the S-EM and (b) Magnified region of (a).

Furthermore, based on the observation and measurement of at least 100 cracks, the crack initiation probability at different sites in the EM and S-EM was obtained during in situ tensile tests, as shown in Figure 15. The probability of crack initiation in the semi-equiaxed $\alpha_{p}$ phase (include the blurry semi- $\alpha_{p} / \beta_{\text {trans }}$ interface) of the S-EM is lower than the equiaxed $\alpha_{\mathrm{p}}$ phase (include the $\alpha_{\mathrm{p}} / \beta_{\text {trans }}$ interface) of the EM, whereas the crack initiation probability increased in the $\beta_{\text {trans }}$ microstructure and GB $\alpha$ of the S-EM in comparison to the EM. This indicates that the special interfacial microstructure of S-EM leads to the reduction of local stress concentration at the blurry interface between semi-equiaxed $\alpha_{p}$ phase and $\beta_{\text {trans }}$ microstructure compared to the $\alpha_{p} / \beta_{\text {trans }}$ interface in the EM. 


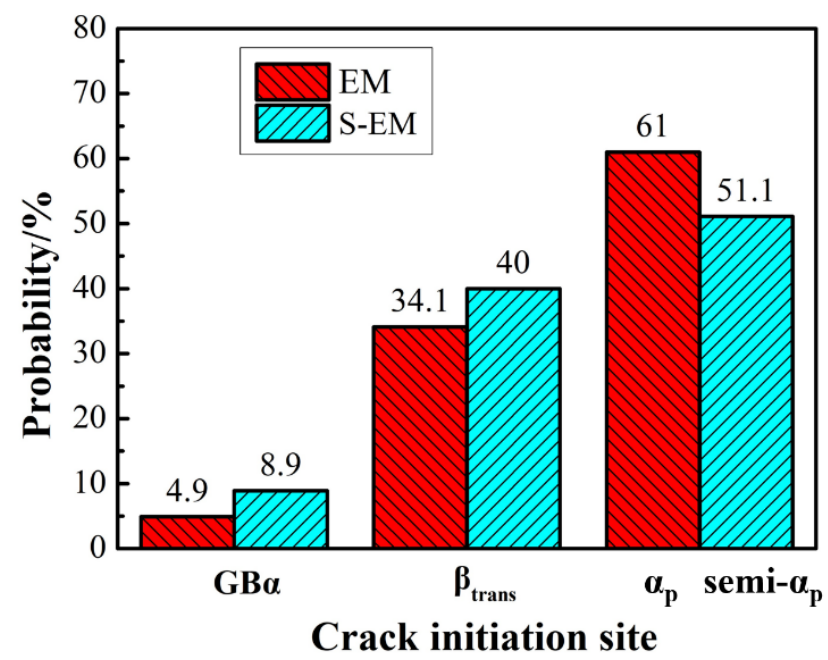

Figure 15. The crack nucleation probability at different sites of the EM and S-EM.

Based on the above observation and discussion of the microstructural characteristic in the EM and S-EM during the tensile deformation, the relationship between slip and the formation of microvoids or cracks is schematically illustrated in Figure 16. When the EM is subjected to a large tensile load, a large number of dislocations pile up at the $\alpha_{\mathrm{p}} / \beta_{\text {trans }}$ interface, resulting in a severe stress concentration at the $\alpha_{p} / \beta_{\text {trans }}$ interface. Therefore, the $\alpha_{p} / \beta_{\text {trans }}$ interface is the preferred initiation site for microvoids or cracks $[10,30]$. Due to the different orientations and short effective slip distances in the $\alpha_{\mathrm{s}}$ lamellae and remnant $\beta_{\mathrm{r}}$ phase, the deformation capacity is relatively poor, resulting in cracks initiating at the $\alpha_{\mathrm{s}} / \beta_{\mathrm{r}}$ interface [31], as shown in Figure 16a. For the S-EM, dense slip bands in the semiequiaxed $\alpha_{\mathrm{p}}$ phase are suppressed by the thin $\beta$ lamellae, and fewer dislocations pile up at the blurry interface between the semi-equiaxed $\alpha_{\mathrm{p}}$ phase and $\beta_{\text {trans }}$ microstructure, which reduces the stress concentration. Then, the probability of crack initiation at the blurry semi- $\alpha_{\mathrm{p}} / \beta_{\text {trans }}$ interface decreases (Figure 16b).

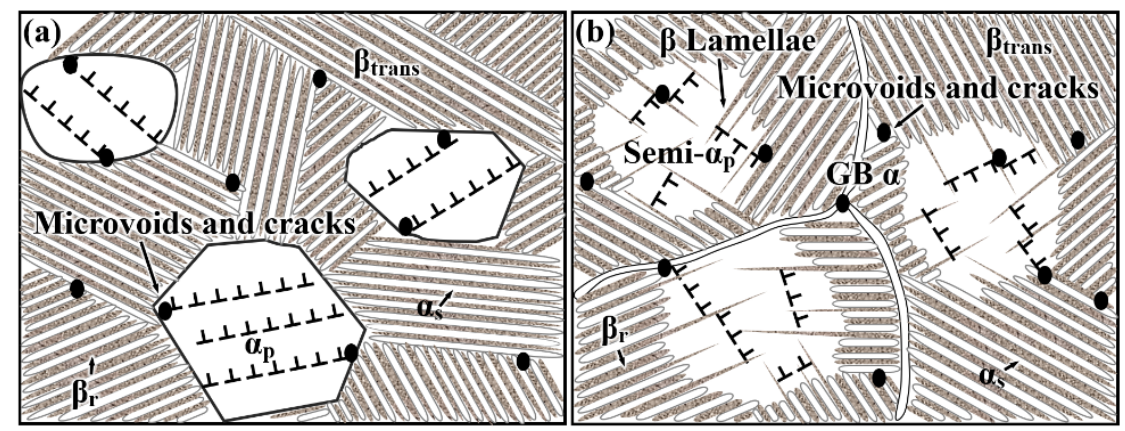

Figure 16. Schematic of the deformation and microvoids or cracks nucleation in different microstructures: (a) EM and (b) S-EM.

\section{Conclusions}

In this work, the deformation behavior and fracture mechanism of the particular S-EM were revealed by in situ tensile tests, and the influence of the microstructural characteristics on the mechanical properties was explored. The main conclusions are summarized as follows:

(1) In the S-EM, the distinct $\alpha_{\mathrm{p}} / \beta_{\text {trans }}$ interface in the bimodal microstructure primarily disappears, and the thin $\beta$ lamellae grow through the equiaxed $\alpha_{\mathrm{p}}$ phase, leading to partial division of the equiaxed $\alpha_{\mathrm{p}}$ phase by the thin $\beta$ lamellae. 
(2) The S-EM effectively suppress the formation of dense slip bands in the semi-equiaxed $\alpha_{p}$ phase, so the stress concentration at the blurry semi- $\alpha_{p} / \beta_{\text {trans }}$ interface in the S-EM has been reduced, and the semi-equiaxed $\alpha_{p}$ phase and $\beta_{\text {trans }}$ microstructure have better deformation compatibility. In addition, the tensile strength of the S-EM is higher than that of the EM due to the thin $\beta$ lamellae hindering the movement of dislocations within the semi-equiaxed $\alpha_{\mathrm{p}}$ phase in the S-EM.

(3) In the S-EM, the prismatic slip and dislocation tangling between the thin $\beta$ lamellae are the main deformation modes of the semi-equiaxed $\alpha_{p}$ phase. The deformation of the $\beta_{\text {trans }}$ microstructure in the S-EM is mainly affected by planar slip and dislocation tangling in the $\alpha_{\mathrm{s}}$ lamellae.

(4) The tensile fracture failures of both EM and S-EM in TA19 alloy show a mixture fracture mode. Compared to the EM, S-EM samples have shallower dimples and more cleavage facets, which leads to the proportion of brittle fracture mechanism of S-EM is slightly larger than EM.

Author Contributions: Conceptualization, M.L. and Y.L. (Yu Liang); methodology, M.L. and Y.L. (Yu Liang); software, M.L. and Y.L. (Yu Liang); validation, M.L. and Y.L. (Yu Liang); formal analysis, M.L. and Y.L. (Yu Liang); investigation, W.L. and T.L.; resources, Y.L. (Yilong Liang); data curation, L.Z. and Y.L. (Yu Liang); writing—original draft preparation, M.L.; writing—review and editing, M.L.; visualization, M.L.; supervision, M.H. and W.L.; project administration, Y.L. (Yu Liang); funding acquisition, Y.L. (Yu Liang). All authors have read and agreed to the published version of the manuscript.

Funding: This work was financially supported by the National Natural Science Foundation of China (No. 51761003 and No. 51461007), Natural Science Foundation of Guizhou Province, China (No. [2017]5788), and One Hundred Person Project of Guizhou Province, China (No. [2020]6006).

Institutional Review Board Statement: Not applicable.

Informed Consent Statement: Not applicable.

Data Availability Statement: Not applicable.

Conflicts of Interest: The authors declare no potential conflict of interest with respect to the research, authorship, and/or publication of this article.

\section{References}

1. Rezaee, M.; Zarei-Hanzaki, A.; Mohamadizadeh, A.; Ghasemi, E. High-temperature flow characterization and microstructural evolution of Ti6242 alloy: Yield drop phenomenon. Mater. Sci. Eng. A 2016, 673, 346-354. [CrossRef]

2. Gao, P.F.; Lei, Z.N.; Li, Y.K.; Zhan, M. Low-cycle fatigue behavior and property of TA15 titanium alloy with tri-modal microstructure. Mater. Sci. Eng. A 2018, 736, 1-11. [CrossRef]

3. Tarzimoghadam, Z.; Sandlöbes, S.; Pradeep, K.G.; Raabe, D. Microstructure design and mechanical properties in a near- $\alpha$ Ti-4Mo alloy. Acta Mater. 2015, 97, 291-304. [CrossRef]

4. Bobbili, R.; Madhu, V. Flow and fracture characteristics of near alpha titanium alloy. J. Alloys Compd. 2016, 684, 162-170. [CrossRef]

5. Jia, W.; Zeng, W.; Yu, H. Effect of aging on the tensile properties and microstructures of a near-alpha titanium alloy. Mater. Des. 2014, 58, 108-115. [CrossRef]

6. Gao, P.F.; Qin, G.; Wang, X.X.; Li, Y.X.; Zhan, M.; Li, G.J.; Li, J.S. Dependence of mechanical properties on the microstructural parameters of TA15 titanium alloy with tri-modal microstructure. Mater. Sci. Eng. A 2019, 739, 203-213. [CrossRef]

7. Banerjee, D.; Williams, J.C. Perspectives on Titanium Science and Technology. Acta Mater. 2013, 61, 844-879. [CrossRef]

8. Zhang, C.J.; Guo, C.X.; Zhang, S.Z.; Feng, H.; Chen, C.Y.; Zhang, H.Z.; Cao, P. Microstructural manipulation and improved mechanical properties of a near $\alpha$ titanium alloy. Mater. Sci. Eng. A 2020, 771, 138569. [CrossRef]

9. Huang, C.W.; Zhao, Y.Q.; Xin, S.W.; Zhou, W.; Li, Q.; Zeng, W. Effect of microstructure on torsion properties of Ti-5Al-5Mo-5V3Cr-1Zr alloy. J. Alloys Compd. 2017, 693, 582-591. [CrossRef]

10. Tan, C.; Sun, Q.; Xiao, L.; Zhao, Y.; Sun, J. Characterization of deformation in primary $\alpha$ phase and crack initiation and propagation of TC21 alloy using in-situ SEM experiments. Mater. Sci. Eng. A 2018, 725, 33-42. [CrossRef]

11. Shao, H.; Zhao, Y.; Ge, P.; Zeng, W. Crack initiation and mechanical properties of TC21 titanium alloy with equiaxed microstructure. Mater. Sci. Eng. A 2013, 586, 215-222. [CrossRef]

12. Huang, C.; Zhao, Y.; Xin, S.; Zhou, W.; Li, Q.; Zeng, W.; Tan, C. High cycle fatigue behavior of Ti-5Al-5Mo-5V-3Cr-1Zr titanium alloy with bimodal microstructure. J. Alloys Compd. 2017, 695, 1966-1975. [CrossRef] 
13. Yang, Y.; Jiang, Z.; Wang, C.; Hu, H.B.; Tang, T.G.; Zhang, H.S.; Fu, Y.N. Effects of the phase interface on initial spallation damage nucleation and evolution in dual phase titanium alloy. Mater. Sci. Eng. A 2018, 731, 385-393. [CrossRef]

14. Huang, C.; Zhao, Y.; Xin, S.; Tan, C.; Zhou, W.; Li, Q.; Zeng, W. Effect of microstructure on high cycle fatigue behavior of Ti-5Al-5Mo-5V-3Cr-1Zr titanium alloy. Int. J. Fatigue 2017, 94, 30-40. [CrossRef]

15. Sadeghpour, S.; Abbasi, S.M.; Morakabati, M.; Bruschi, S. Correlation between alpha phase morphology and tensile properties of a new beta titanium alloy. Mater. Des. 2017, 121, 24-35. [CrossRef]

16. Attallah, M.M.; Preuss, M.; Boonchareon, C.; Steuwer, A.; Daniels, J.E.; Hughes, D.J.; Dungey, C.; Baxter, G.J. Microstructural and Residual Stress Development due to Inertia Friction Welding in Ti-6246. Metall. Mater. Trans. A 2012, 43, 3149-3161. [CrossRef]

17. Wang, G.; Chen, Z.; Li, J.; Liu, J.; Wang, Q.; Yang, R. Microstructure and Mechanical Properties of Electron Beam Welded Titanium Alloy Ti-6246. J. Mater. Sci. Technol. 2018, 34, 570-576. [CrossRef]

18. Xu, P.; Zhou, L.; Han, M.; Wei, Z.; Liang, Y. Flash-butt welded Ti6242 joints preserved base-material strength and ductility. Mater. Sci. Eng. A 2020, 774, 138915. [CrossRef]

19. Han, M.; Xu, P.; Wan, M.; Liang, Y.; Du, J. Semi-equiaxed Structure and Tensile Properties of TA19 Titanium Alloy. Rare Met. Mater. Eng. 2018, 47, 3768-3775.

20. ASTM International. Standard Guide for Preparation of Metallographic Specimens; ASTM International: West Conshohocken, PA, USA, 2011.

21. Steel, S.; Axial, C.; Application, F. E8/E8M Standard Test Methods for Tension Testing of Metallic Materials; ASTM International: West Conshohocken, PA, USA, 2011.

22. Qin, D.; Lu, Y.; Guo, D.; Zheng, L.; Liu, Q.; Zhou, L. Tensile deformation and fracture of Ti-5Al-5V-5Mo-3Cr-1.5Zr-0.5Fe alloy at room temperature. Mater. Sci. Eng. A 2013, 587, 100-109. [CrossRef]

23. Mayeur, J.R.; McDowell, D.L. A three-dimensional crystal plasticity model for duplex Ti-6Al-4V. Int. J. Plast. 2007, 23, 1457-1485. [CrossRef]

24. Tan, C.; Li, X.; Sun, Q.; Xiao, L.; Zhao, Y.; Sun, J. Effect of $\alpha$-phase morphology on low-cycle fatigue behavior of TC21 alloy. Int. J. Fatigue 2015, 75, 1-9. [CrossRef]

25. Gao, P.; Cai, Y.; Zhan, M.; Fan, X.; Lei, Z. Crystallographic orientation evolution during the development of tri-modal microstructure in the hot working of TA15 titanium alloy. J. Alloys Compd. 2018, 741, 734-745. [CrossRef]

26. Seshacharyulu, T.; Medeiros, S.C.; Morgan, J.T.; Malas, J.C.; Frazier, W.G.; Prasad, Y.V.R.K. Hot deformation and microstructural damage mechanisms in extra-low interstitial (ELI) grade Ti-6Al-4V. Mater. Sci. Eng. A 2000, 279, 289-299. [CrossRef]

27. Chong, Y.; Deng, G.; Gao, S.; Yi, J.; Shibata, A.; Tsuji, N. Yielding nature and Hall-Petch relationships in Ti-6Al-4V alloy with fully equiaxed and bimodal microstructures. Scr. Mater. 2019, 172, 77-82. [CrossRef]

28. Yu, H.; Xin, Y.; Wang, M.; Liu, Q. Hall-Petch relationship in Mg alloys: A review. J. Mater. Sci. Technol. 2018, 34, 248-256. [CrossRef]

29. Liu, C.; Lu, Y.; Tian, X.; Liu, D. Influence of continuous grain boundary $\alpha$ on ductility of laser melting deposited titanium alloys. Mater. Sci. Eng. A 2016, 661, 145-151. [CrossRef]

30. Yan, Z.; Wang, K.; Zhou, Y.; Zhu, X.; Xin, R.; Liu, Q. Crystallographic orientation dependent crack nucleation during the compression of a widmannstätten-structure $\alpha / \beta$ titanium alloy. Scr. Mater. 2018, 156, 110-114. [CrossRef]

31. Liu, R.; Hui, S.; Ye, W.; Yu, Y.; Fu, Y.; Song, X.; Deng, X. Tensile and fracture properties of Ti-62A alloy plate with different microstructures. Rare Met. 2012, 31, 420-423. [CrossRef] 